\title{
Application of poly(ethylene glycol)- distearoylphosphatidylethanolamine (PEG-DSPE) block copolymers and their derivatives as nanomaterials in drug delivery
}

This article was published in the following Dove Press journal:

International Journal of Nanomedicine

3I July 2012

Number of times this article has been viewed

\author{
Rongrong Wang' \\ Renzhong Xiao ${ }^{2}$ \\ Zhaowu Zeng ${ }^{2}$ \\ Lili Xu ${ }^{2}$ \\ Junjie Wang ${ }^{2}$ \\ 'Campus Hospital of Zhejiang \\ University, ${ }^{2}$ Research Center for \\ Biomedicine and Health, Hangzhou \\ Normal University, Hangzhou, China
}

\begin{abstract}
Poly(ethylene glycol)-distearoylphosphatidylethanolamine (PEG-DSPE) block copolymers are biocompatible and amphiphilic polymers that can be widely utilized in the preparation of liposomes, polymeric nanoparticles, polymer hybrid nanoparticles, solid lipid nanoparticles, lipid-polymer hybrid nanoparticles, and microemulsions. Particularly, the terminal groups of PEG can be activated and linked to various targeting ligands, which can prolong the circulation time, improve the drug bioavailability, reduce undesirable side effects, and especially target specific cells, tissues, and even the intracellular localization in organelles. This review herein aims to describe recent developments in drug carriers exploiting PEG-DSPE block copolymers and their derivatives, and the incorporation of different ligands to the end groups of PEG-DSPE to target delivery, focusing on their modification approaches, advantages, applications, and the probable associated drawbacks.
\end{abstract}

Keywords: PEG-DSPE, PEG-lipid, Mal-PEG-DSPE, targeting delivery

\section{Introduction}

Poly(ethylene glycol)-distearoylphosphatidylethanolamine (PEG-DSPE) block copolymers are amphiphilic, have been approved by the Food and Drug Administration for medical applications, ${ }^{1}$ and have been widely used in the preparation of liposomes, polymeric nanoparticles, polymer hybrid nanoparticles, and solid lipid nanoparticles, among others. The amphiphilic polymers are nanostructures composed by a hydrophobic core (DSPE) and a hydrophilic shell (PEG). The core-shell structure can encapsulate and carry poorly water-soluble drugs to congregate in the core of DSPE, and the PEG shell reduces the in vivo clearance of cholesterol-free liposomal formulations and the adsorption of plasma proteins. ${ }^{2}$ Therefore, utilizing PEG-DSPE for the formation of nanostructures could prolong the body circulation time and release drugs at a sustained rate in an optimal range of drug concentrations. ${ }^{3}$ Besides, the percentage content of PEG-DSPE significantly affects the sizes of vesicles. DSPE-PEG ${ }_{2000}$-containing egg-yolk phosphatidylcholine vesicles have been prepared utilizing the detergentremoval method by Sriwongsitanont and Ueno, ${ }^{4}$ which verified that the vesicles' inclusion of DSPE-PEG ${ }_{2000}$ promoted vesicle formation, and the incorporation of increasing amounts of PEG lipid in liposomes reduced liposome sizes. 
Molecular therapy, including gene therapy, is a promising strategy for the treatment of human diseases. However, delivery of molecular therapeutics efficiently and specifically to the targeted tissue remains a significant challenge. Luckily, researchers have discovered that in vivo tumor targeting can be achieved by encapsulating genes into nanocarriers due to their enhanced permeability and retention effect. ${ }^{5}$ Moreover, the terminal groups of PEG can be activated and linked to various targeting ligands on the surface of nanocarriers, which has been demonstrated to increase delivery efficiency and tissue specificity. ${ }^{6}$ In this paper, we have critically reviewed and assessed the PEG-DSPE block copolymers being used to construct nanocarrier systems and deliver nucleic acids, proteins and peptides. In addition, a comprehensive summary is presented on activating the terminal groups of PEG and further functionalization with targeting ligands for different types of delivery.

\section{Synthesis of PEG-DSPE end-group derivatives}

The commonly used lipid derivative of PEG is methoxy-PEGDSPE with a methoxy terminal. Although methoxy-PEGDSPE can prolong liposomes circulation, the methoxy group is too inactive to react with the ligands in mild conditions. Therefore, it is necessary to modify PEG-DSPE with terminal groups mainly consisting of the hydroxyl in order to link with certain ligands. Through modifying the hydroxyl of the PEG end-group, the physical and chemical properties of the polymers can be improved in targeted drug delivery. ${ }^{7,8}$ The common end-group forms of PEG-DSPE derivatives include carboxylation, amination, and maleylation.

\section{Carboxyl-terminated PEG-DSPE}

Carboxyl groups are introduced to the terminal groups of PEG-DSPE block copolymers, which can easily react with the ligands for active target cells or tissues, such as transferring and peptide. ${ }^{9-11}$ Several reports have successfully synthesized DSPE-PEG-COOH. ${ }^{12-14}$ In brief, DSPE in chloroform methanol was added to PEG-bis(succinimidyl succinate) (PEG-2OSu) in chloroform, followed by the addition of triethylamine. The reaction mixture was stirred vigorously overnight at room temperature. Full conversion of the primary amino group of DSPE was confirmed by the negative ninhydrin reactivity after separating the products by thin-layer chromatography.

Vaidya et al ${ }^{10}$ prepared arginine-glycine-aspartic acid (RGD)-conjugated PEGylated liposomes utilizing DSPE-PEG-COOH to conjugate with the amine group of
c(RGD) peptide (CNPRGDY[OEt]RC). Compared to the plain streptokinase solution and long circulatory liposomes, the RGD peptide-conjugated liposomes accumulated at the site of the blood clot and increased the thrombolytic activity.

\section{Amino-terminated PEG-DSPE (amino-PEG-DSPE)}

The amino group of the heterobifunctional PEG is selectively protected by such protective groups as fluorenylmethyloxycarbonyl and butyloxycarbonyl (Boc). The other end of PEG is the active group that reacts with DSPE. The protective groups are then removed after the reaction to form aminoPEG-DSPE. Also, amino-PEG-DSPE can be combined with small-molecule medicines and ligands.

Zalipsky et $\mathrm{al}^{15}$ synthesized the following amino-PEGDSPE (Figure 1). First, the amino group of the heterobifunctional PEG was selectively protected by the Boc group. Secondly, a succinimidyl carbonate (SC) group was introduced at the hydroxyl end of $\alpha$-Boc- $\omega$-hydroxy-PEG to form urethane linking the amino group of DSPE and the primary amine functionality of the PEG regenerated by the acidolytic removal of the Boc group.

\section{Hydrazide-terminated PEG-DSPE (Hz-PEG-DSPE)}

Ligands can also be covalently bound to the hydrazide groups grafted onto PEG-DSPE to form a hydrazide bond.

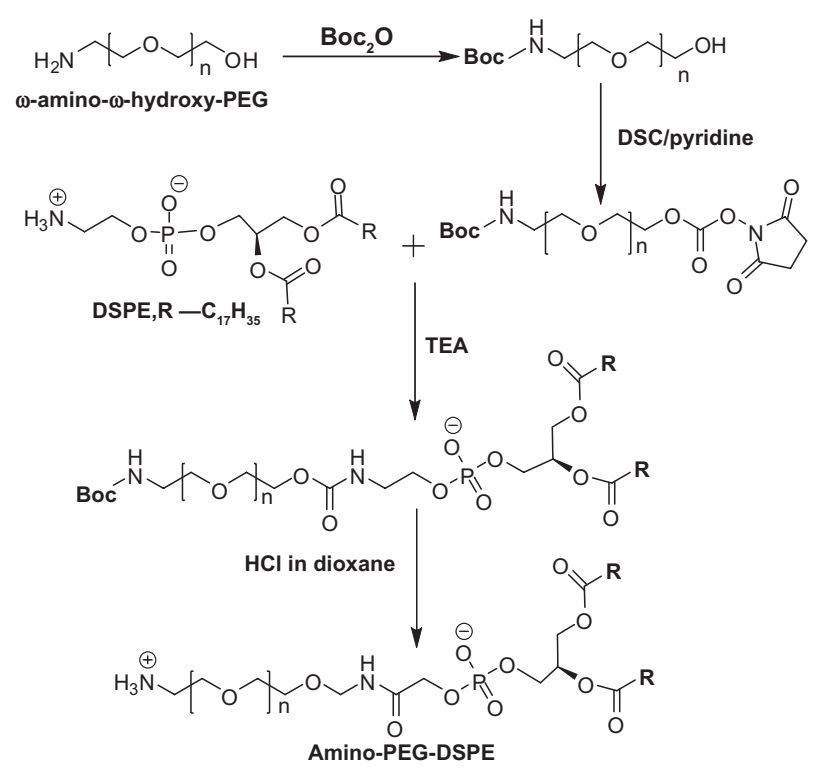

Figure I Synthesis of amino-PEG-DSPE. 15

Abbreviations: PEG, polyethylene glycol; Boc, tert-butyloxycarbonyl; DSPE, I,2-distearoyl-sn-glycero-3-phosphoethanolamine; TEA, triethylamine. 
Oxidized ligands have been reported to react with the hydrazide groups of the anchor to form Hz-PEG-DSPE. ${ }^{16,17}$

Zalipsky ${ }^{18}$ prepared the heterobifunctional PEG derivative by modifying one end with an SC group, and the other terminal with a tert-Boc protected the hydrazide group. Then the reaction of Boc-PEG-SC and the amino group of DSPE readily produced Boc-PEG-DSPE. Finally, acidolytic removal of the Boc group yielded Hz-PEG-DSPE conjugate suitable for linking various ligands.

The above method has been successfully utilized to synthesize various ligand-modified PEG-DSPE copolymers for targeting drug-delivery systems. ${ }^{19-21}$

\section{Maleimide-terminated PEG-DSPE (Mal-PEG-DSPE)}

Recently, PEG-DSPE modified with a maleimide group at the distal terminal of the PEG chain is widely used in targeted delivery systems due to its convenient and rapid reaction with ligands such as antibody and peptide. ${ }^{22,23}$

Two methods have been successfully employed to synthesize Mal-PEG-DSPE (Figure 2). ${ }^{24}$ In the first method, amino-PEG-DSPE reacted with $N$-succinimidyl3-( $N$-maleimido)-propionate in $\mathrm{CH}_{2} \mathrm{Cl}_{2}, \mathrm{DMF}$, and triethylamine to form Mal-PEG-DSPE. In the second method, $\omega-(\beta-[N$-maleimido])-PEG- $\alpha$-succinimidyl carboxylate (MalPEG-SC) reacted with DSPE and triethylamine in chloroform.

\section{Reasonable selection of targeted moieties in the modification of the PEG-DSPE end groups}

Targeted drug-delivery systems have been recognized as a promising strategy to improve the selective targeting of drugs to the diseased tissues, leading to improved treatment

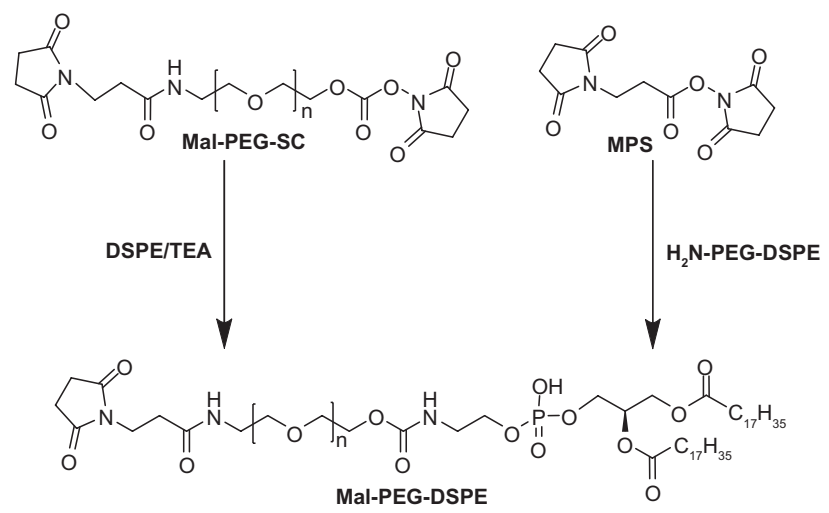

Figure 2 Synthesis procedure of maleimide-PEG-DSPE. ${ }^{24}$

Abbreviations: Mal, $\beta$-( $N$-maleimido) propionyl; Mal-PEG-SC, $\omega$-Mal- $\alpha$-succinimidyl carboxylate; MPS, $\mathrm{N}$-(maleimido-propionyloxy)-succinimide ester; TEA, triethylamine. efficacy and reduced drug toxicity. Especially, a variety of targeting moieties such as antibodies, growth factors, or cytokine functioning have been used as vehicles to introduce drugs, proteins, and nucleic acids into target cells. ${ }^{25-27}$ The end groups of PEG-DSPE were easily grafted to different targeting moieties, which are mainly divided into nonantibody ligand-targeting moieties and antibody ones.

\section{Nonantibody targeting moieties}

Owing to microenvironmental changes, some cells or tissues express high levels of special receptors, whereas normal tissues express low or undetectable receptor levels. ${ }^{28}$ Thus it is possible to target special receptors with ligands linked to extremities of PEG-DSPE to deliver drugs to the target sites. For example, nontargeted PEGylated liposomes in experimental tumors indicated that their distribution was limited to the extracellular fluid and tumor-infiltrating macrophages, but folate (FA)-targeted ones would deliver the drug cargo into folate receptor (FR)-expressing tumor cells, which provided a more potent antitumor effect than limiting in the gradual extracellular distribution to the extracellular fluid. ${ }^{29,30}$

Nonantibody ligands are often readily available, inexpensive to manufacture, and easy to handle, the adverse effects of which mainly originate from their relatively nonselective expression. ${ }^{31}$ It is therefore necessary to choose appropriate methods and target ligands for modification of the PEGDSPE end groups. To date, many nonantibody targeting moieties (Table 1) have been grafted to PEG-DSPE for cancer therapeutics.

\section{Antibody targeting moieties}

Antibody-mediated targeting therapeutics have been explored with the development of antibody engineering and phagedisplay technologies, ${ }^{43-45}$ which have been employed to realize high specificity for the target tissues, a wide range of binding affinities, and small molecular sizes. When proper antibodies are linked to the reactive terminal of PEG-DSPE, the carriers can be targeted to the selected tissue, depending on the ability of the antibody or ligand that facilitates cell-specific docking. ${ }^{46}$ For instance, anti-CD22 monoclonal antibody specifically bound with the CD22 surface antigen expression in non-Hodgkin's lymphoma cells. A postinsertion method was adopted to incorporate anti-CD22-PEG-DSPE into the liposomes containing cancer drugs. The anti-CD22 immunoliposomes exhibited increased efficacy and reduced toxicity compared to the unmodified ones. ${ }^{47}$ Also, Lopes de Menezes et al ${ }^{48}$ prepared doxorubicin (DXR) immunoliposomes that were coupled to monoclonal antibody (MAb) anti-CD19 against malignant B cells. 
Table I Nonantibody targeting moieties grafted to PEG-DSPE for cancer therapeutics

\begin{tabular}{|c|c|c|c|}
\hline Nonantibody targeting moieties & Target & Target cells or tissues & References \\
\hline Folate & Folate receptor & $\begin{array}{l}\text { Cancer cells that overexpress } \\
\text { the folate receptor }\end{array}$ & 30,32 \\
\hline Transferrin & Transferrin receptor & $\begin{array}{l}\text { Cancer cells that overexpress } \\
\text { the transferrin receptor }\end{array}$ & 33,34 \\
\hline Asn-Gly-Arg (NGR) & Aminopeptidase N (CDI3) & Vasculature endothelial cells & 26,35 \\
\hline Leu-Ala-Arg-Leu-Leu-Thr (D4) or GEI I & $\begin{array}{l}\text { Epidermal growth factor } \\
\text { receptor (EGFR) }\end{array}$ & $\begin{array}{l}\text { Cancer cells that } \\
\text { overexpress EGFR }\end{array}$ & 6,36 \\
\hline Galactose residues & $\begin{array}{l}\text { Hepatic asialoglycoprotein } \\
\text { receptor (ASGP-R) }\end{array}$ & Activated platelets, hepatocyte & 37,38 \\
\hline Arg-Gly-Asp (RGD) & Integrins & Vasculature endothelial cells & 39,40 \\
\hline Anisamide ligand & Sigma receptor & Human lung cancer cells & 41 \\
\hline Vasoactive intestinal peptide (VIP) & VIP receptors & Breast cancer & 42 \\
\hline
\end{tabular}

Abbreviations: NGR, asparagine- glycine- arginine; CDI3, Aminopeptidase N; D4, leucine-alanine-arginine-leucine-leucine-threonine; GEII, an amino acid sequence YHWYGYTPQNVI; EGFR, epidermal growth factor receptor; ASGP-R, hepatic asialoglycoprotein receptor; RGD, arginine-glycine-aspartic acid; VIP, Vasoactive intestinal peptide.

The binding with immunoliposomes (anti-CD19) resulted in a threefold higher association of the immunoliposomes with human CD19+ B-lymphoma cell line (Namalwa) in comparison with the nontargeted liposomes. Nontargeted liposomes exhibited an apparently lower recognition of either B cells or T cells than the targeted DXR immunoliposomes (anti-CD19). In addition, many antibody targeting moieties listed in Table 2 have been researched for targeting delivery by being grafted to the end groups of PEG-DSPE.

MAbs have been utilized to modify the terminal group of PEG-DSPE for targeting delivery in the form of either whole MAbs or MAb fragments, including Fab' and single-chain variable region fragments (scFv). ${ }^{49-51}$ MAbs contains fragments (Fab), complementarity-determining regions and fragmentcrystallizable region $(\mathrm{Fc})$, but fragments do not include Fc. Their targeting are somewhat different. PEG-DSPE derived with MAb fragments could increase the circulation time in blood compared to the particulates derived with whole MAbs, which was ascribed to the fact that the former was lack of the Fc domain binding to Fc receptors on phagocytic cells. ${ }^{52}$ Cheng and Allen ${ }^{53}$ developed an anti-CD19 liposomal for the targeting delivery of DXR in B-cell lymphoma and compared to the result with those of the whole monoclonal antibody, Fab' fragments, and scFv. Pharmacokinetics and biodistribution studies showed that immunoliposome-DXR targeted via Fab', which had the longest circulation half-life, appeared to be slightly more effective in prolonging the survival time than that targeted via either scFv or mAb, because immunoliposome-DXR targeted via Fab' reduced Fc-mediated uptake in liver and spleen.

\section{Strategies of adsorbing ligands onto the vector surface}

In general, the methods of adsorbing ligands to the vector surface should be simple, fast, and efficient, with stable yield

Table 2 Antibody targeted moieties grafted to PEG-DSPE for targeted delivery

\begin{tabular}{|c|c|c|c|}
\hline Antibody targeting moieties & Target & Target cells or tissues & References \\
\hline Anti-CDI9 & CDI9 epitope & B lymphoma cells & 48,54 \\
\hline Anti-CD20 & CD20, a B-cell surface antigen & B-cell malignancies & 46,55 \\
\hline Anti-CD22 & CD22, a B-cell surface antigen & $\begin{array}{l}\text { Non-Hodgkin's lymphoma and other B-cell } \\
\text { lymphoproliferative diseases }\end{array}$ & 47,56 \\
\hline Anti-CD33 & CD33, a T-cell epitope & Myeloid leukemia cells & 50 \\
\hline Anti-ErbB2 & ErbB2 receptor & Cancer cells overexpressed the ErbB2 receptor & 57,58 \\
\hline Anti-CEA & CEA & $\begin{array}{l}\text { Cancer cells that overexpress the CEA such } \\
\text { as pancreatic cancer cells, small-cell lung cancer cells }\end{array}$ & 59,60 \\
\hline Antagonist G & - & Small-cell lung cancer & 61,62 \\
\hline Anti-HER2 & HER2 & Breast cancer cells & 24 \\
\hline EGF & EGF receptor & Human glioma cells & 63 \\
\hline Anti-GD2 & Disialoganglioside (GD2) & Neuroblastoma & 64 \\
\hline CC52 & CC53I & Colon cancer cells & 65 \\
\hline
\end{tabular}

Abbreviations: CDI9, the cluster of differentiation 19 is a protein that in humans is encoded by the CDI9 gene; CD20, cluster of differentiation 20; CD22, cluster of differentiation 22; CD33, cluster of differentiation 33; ErbB2/HER2, human epidermal growth factor receptor 2; CEA, carcinoembryonic antigen; EGF, epidermal growth factor; GD2, disialoganglioside; CC52, a murine lgGI monoclonal antibody; CC53I, a cell line was induced by treatment of WAG rats with I,2 dimethylhydrazine. 
and nontoxic bonds. Furthermore, the target recognition and binding efficiency should not be substantially altered. Two approaches consisting of noncovalent and covalent coupling are commonly exploited for attaching ligands to the vector surface. The former merely adds the ligand to the mixture as one of the prescription components during the preparation of the vector. ${ }^{66}$ However, it suffers from the following unfavorable disadvantages: (1) the low percentage of ligands attached to the carrier; (2) the aggregation of ligands on the surface of carriers; (3) the difficulty of controlling and orienting the antibodies; and (4) possible detachment of the antibody in vivo. ${ }^{67}$ Consequently, this method is rarely used nowadays.

On the contrary, covalent coupling appears to be effective in fixing ligands to the carriers, owing to the much more stable and reproducible linkage compared to that formed by the noncovalent method. The three main strategies covalently coupling ligands to the surface vector are listed below.

\section{Addition of ligand-PEG-DSPE as components during the preparation of carriers}

Ligand-PEG-DSPE can self-assemble into micelles, which are prepared into liposomes with phospholipids and cholesterol delivering the loading drug into target cells or tissues, thereby improving bioavailability and reducing toxicity (Figure 3A). ${ }^{68,69}$

A multifunctional nanoassembly system for the codelivery of docetaxel and iSur-pDNA was reported by $\mathrm{Xu}$ et al, ${ }^{70}$ by utilizing folate-PEG-DSPE as the target. The result showed the particle size was about $200 \mathrm{~nm}$ and the encapsulation efficiency was higher than $90 \%$. Compared with free docetaxel and iSur-pDNA, better antitumor efficacy as well as low systemic toxicity could be observed. The product displayed better antitumor efficacy and lower systemic toxicity compared to the free docetaxel and iSur-pDNA.

The drug-loaded folate-conjugated micelles encapsulating the anticancer agent 9-nitro-camptothecin (9-NC) were successfully prepared by the film-formation method. ${ }^{71}$ These micelles have low average size, high encapsulation and drugloading efficiency, and particularly higher antitumor activity than those of drug-loaded MPEG-DSPE micelles and free anticancer agents.

However, mixing ligand-PEG-DSPE with other components would lead to some drawbacks, including the possible presence of the ligands on the inner surface of the carriers and the consequent unavailability to target cells or tissues. Furthermore, the number of ligands coupled to the carrier surface can be rather nonuniform.

\section{Direct coupling method}

The direct coupling method includes two steps: first preparing DSPE-PEG-activate group-grafted carriers and then coupling ligands to the carriers in a mild reaction condition (Figure 3B). For example, immunoliposomes were obtained by attaching the antibody directly to the bilayer of liposomes containing either Mal-PEG-DSPE or Hz-PEG-DSPE, which would retain the ligands on the surface of the liposome. But the ligands would incorporate into PEG-DSPE with a lower productivity, and the excessive reactants could hardly be removed in the delivery systems.

Maruyama et $\mathrm{al}^{14}$ prepared the following three types of monoclonal antibody 273-34A (34A) immunoliposomes: (1) PEG-free immunoliposomes with the antibody covalently linked to the short anchor 34A; (2) PEG-immunoliposomes with the antibody covalently linked to 34A; (3) PEGimmunoliposomes with $34 \mathrm{~A}$ directly attached to the distal terminal of DSPE-PEG-COOH. The lung-binding efficiency of 34A-Type 2 was 0.5 -fold higher than that of 34A-Type 1 , which could be attributed to the reduced immunospecific antibody-antigen binding and reticuloendothelial system (RES) uptake owing to the steric hindrance of PEG chains. Also, the lung-binding ability of 34A-Type 3 was about 1.3-fold higher than that of 34A-Type 1, indicating that the recognition by the antibodies attached to the PEG terminal was not sterically hindered and the free PEG (ie, that was not carrying antibody) was effective in increasing the blood concentration of immunoliposomes by inhibiting RES uptake.

Lopes de Menezes et $\mathrm{al}^{48}$ synthesized anti-CD19 immunoliposomes by the hydrazide coupling method. The MAb was oxidized firstly with sodium periodate, which was then incubated with hydrazide derivatized PEG-liposomes overnight. Finally, the immunoliposomes were separated from the free $\mathrm{mAb}$ over an equilibrated Sephadex CL-4B column.

\section{Postinsertion method}

Recently, researchers have prepared ligand-targeted liposomes utilizing the postinsertion method. ${ }^{50,72}$ First, ligands such as maleimide and succinyl were coupled to the active end group of PEG-DSPE. Secondly, the ligand-PEG-DSPE was transferred into the outer monolayer of preformed, drug-loaded liposomes by simple incubation ${ }^{50,73}$ (Figure 3C). During the postinsertion method, a variety of ligand-PEGDSPE copolymers were inserted into various preformed liposomes containing different drugs, allowing ligandtargeted therapeutics in individual patients. ${ }^{74}$ 


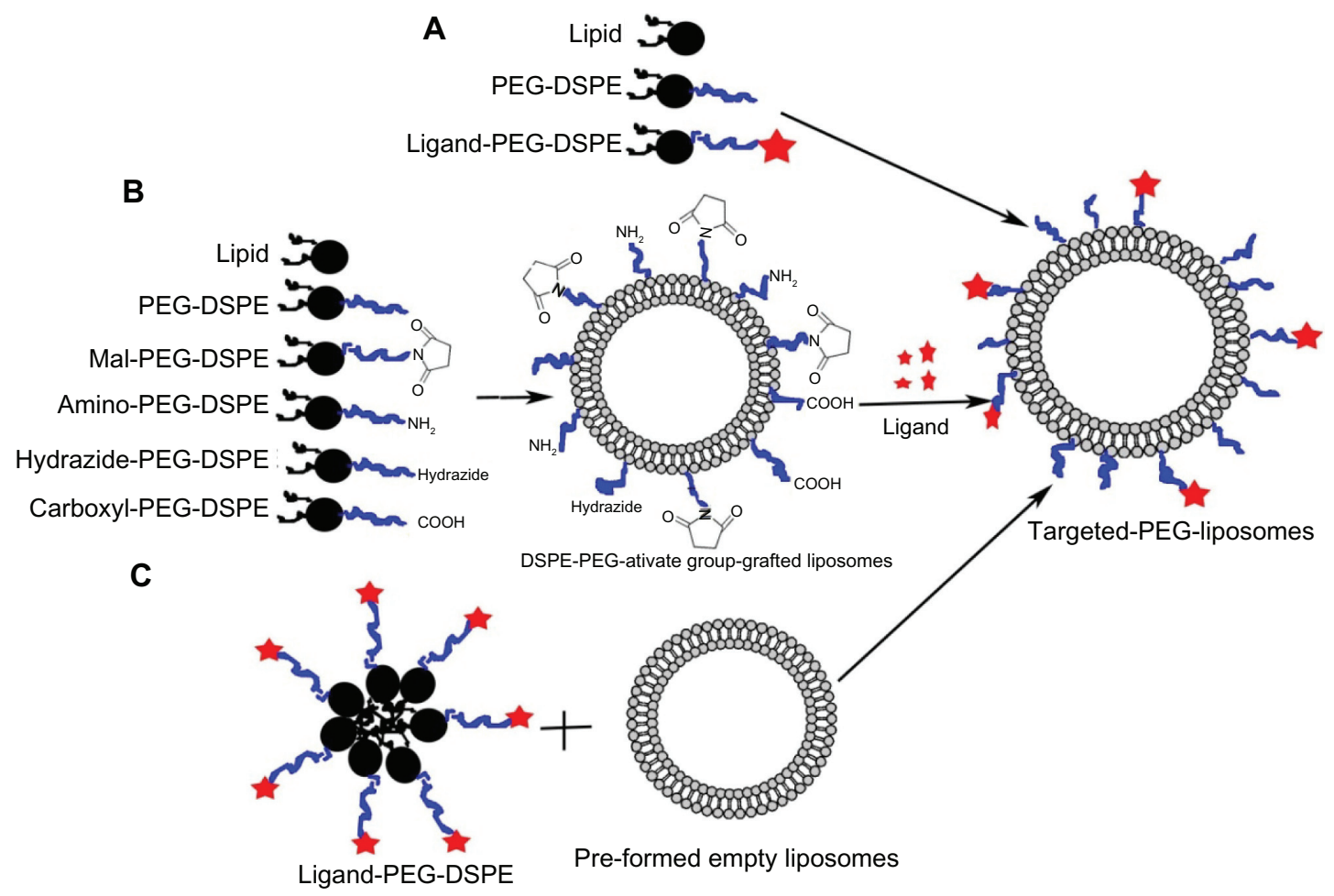

Figure 3 (A-C) Strategies of adsorbing ligands onto the vector surface. (A) Ligand-PEG-DSPE were added as the components during the preparation of carriers; (B) Mal-PEG-liposomes were preformed, then the ligands were directly coupled to the preface; (C) the postinsertion method.

Abbreviations: Mal, $\beta$-(N-maleimido) propionyl; PEG-DSPE, poly(ethylene glycol)-distearoylphosphatidylethanolamine.

Moreover, investigations ${ }^{73,75}$ have shown that the post-insertion liposomes composed of monoclonal antibody anti-CD19-PEG-DSPE conjugates are simple, rapid, and flexible compared to those prepared by conventional coupling procedures, such as the Mal-PEG-DSPE coupling method. But the association results of the targeted liposomes to $\mathrm{CD} 19^{+}$ human B-cell lymphoma cells were similar to those obtained with anti-CD19-targeted liposomes prepared by conventional coupling techniques, and the binding was significantly stronger than that of the nontargeted liposomes.

Furthermore, Vader et al ${ }^{76}$ prepared liposome-polycationDNA (LPD) particles for vascular endothelial growth factor receptor 2 (VEGFR-2) siRNA delivery to tumors, which were modified with a cyclic RGD peptide that specifically bound to integrins expressed by tumor-associated endothelial cells. Then they were optimized with respect to their sizes and charges by varying the contents of protamine and carrier DNA for stronger complexation and higher PEGylation density. The uptake and silencing performance of the RGD-targeted PEGylated LPD particles was evaluated in murine endothelial and human umbilical vein endothelial cells. Compared to the nontargeted LPD particles, enhanced uptake and silencing of VEGFR-2 expression were observed for RGD-targeted PEGylated LPD particles.

\section{Application of PEG-DSPE block- copolymer in the preparation of drug carriers}

The amphiphilic PEG-DSPE block copolymers contain both a hydrophilic PEG segment and a hydrophobic DSPE segment, which can self-assemble into a variety of micellar structures. Moreover, the PEG-DSPE block copolymers have been employed to prepare PEGylated liposomes, which are biocompatible, inert, and could be characterized by a long half-life in the plasma compartment in vivo.

\section{Liposomes}

Conventional liposomes have low bioavailability and short blood-circulation time, and are easily absorbed by the RES..$^{77,78}$ Strategies have been developed to overcome these difficulties by coating the surface of the liposomes with hydrophilic polymers or a glycolipid, such as PEG or monosialoganglioside (GMI). ${ }^{79,80}$ PEG possesses high flexibility, favorable hydrophilicity, antiphagocytosis against macrophages, resistance to immunological recognition, noncombination with proteins, and biocompatibility, ${ }^{81-84}$ which enable the extensive application in developing the PEGylated liposomes for delivering various drugs. 
PEGylated liposomes have attracted considerable attention as the passive targeting administration carriers for the therapy of cancer and infectious diseases. They outweigh other carriers in increasing the systemic circulation time of drugs, delivering active molecules to the site of action and preventing damage of healthy tissue from toxic effects. During the preparation, the key step of developing longcirculating liposomes was accompanied by the inclusion of the synthetic polymer PEG in the liposome composition, such as PEG-DSPE. ${ }^{85,86}$

The incorporation of PEG-DSPE in the lipid-based carriers substantially prolongs the circulation lifetime of the liposomes. Dos Santos et $\mathrm{al}^{2}$ demonstrated that merely $0.5 \mathrm{~mol} \%$ of $\mathrm{PEG}_{2000}$-DSPE would significantly increase the plasma circulation longevity of the liposomes from 1,2-distearoyl-sn-glycero-3-phosphatidylcholine (DSPC). The aggregation of DSPC-based liposomes was completely precluded with $2 \mathrm{~mol} \% \mathrm{PEG}_{2000}$-DSPE, suggesting that $\mathrm{PEG}_{2000}$-DSPE reduced the in vivo clearance of cholesterolfree liposomal formulations and the adsorption of plasma proteins primarily by inhibiting surface interactions and particularly by liposome-liposome aggregation.

The pharmacokinetics, biodistribution, and therapeutic efficacy of the PEGylated liposomes containing cisplatin and nonliposomal cisplatin were compared by Newman et al. ${ }^{87}$ They found that PEGylated liposomes had superior antitumor activity, lower kidney toxicity, and a prolonged circulation time, and also showed a 55-fold higher distribution volume, threefold higher peak plasma levels, and 60-fold larger plasma under the plasma concentration time curve (AUC) compared to those of cisplatin. Moreover, PEGylated liposome-treated animals displayed a 28-fold higher tumor AUC than for cisplatin.

\section{Polymeric nanoparticles}

Polymeric nanoparticles (NPs) may be obtained with the structure of a hydrophobic core and a hydrophilic shell by the self-assembly of biodegradable amphiphilic copolymers. The core-shell structure of polymeric NPs is advantageous in the entrapment of poorly water-soluble drugs, increase of circulating half-life, sustained drug-release profiles, and the functional surface with targeting ligands for differential delivery ${ }^{88,89}$ The most commonly and extensively used amphiphilic copolymers contain PEG-poly-D,L-lactide-coglycolide (PEG-PLGA), PEG-polylactic acid (PEG-PLA), poly-epsiv-caprolactone (PEG-PCL), and PEG-DSPE. ${ }^{90-93}$ In this review, polymeric NPs are limited to nanomicelles, nanospheres and nanocapsules containing PEG-DSPE or their derivatives.
The amphiphilic polymers of PEG-DSPE can selfassemble into micelles and are easily modified. There is a type of satisfactory polymeric NP material for the preparation of polymeric NPs. Gill et al ${ }^{69}$ prepared $\mathrm{PEG}_{5000}-\mathrm{DSPE}$ micelles containing paclitaxel by solvent evaporation, the release of which was investigated in vitro and in vivo. In addition, the toxicological profile of $\mathrm{PEG}_{5000}$-DSPE was also investigated, revealing that the PEG-lipid micelles exhibited a sustained releasing behavior in the simulated lung fluid. The accumulation of paclitaxel in lungs by intravenous $\mathrm{AUC}_{0-12}$ was 45 -fold higher than that of the intravenously administered formulation and threefold higher than that of the intratracheally delivered taxol. Simultaneously, other nontargeted tissues and plasma showed substantially lower paclitaxel concentrations compared to those of other groups. Moreover, toxicity studies exhibited no significant increase in the levels of lung injury markers in the $\mathrm{PEG}_{5000}$-DSPE-treated group compared to those in the saline-treated group.

Hattori and Maitan ${ }^{94}$ prepared folate-linked NPs based

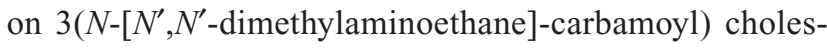
terol (DC-Chol), FA-PEG 2000 -DSPE, and Tween 80, which then formed injectable nanoplexes with high transfection of luciferase gene in human oral and prostate cancer cells. Thus the nanocarrier is potentially useful as a prostate tumorspecific vector for gene therapy.

Recently, several nanomicelle compositions including ligand-PEG-DSPE for the active targeting in anticancer therapy have been investigated in vitro and in vivo. Nanomicelles provided controlled/sustained-release properties and sitespecific targeting of cells or tissues. Moreover, cytotoxicity and higher cellular uptake have also been demonstrated. Han et $\mathrm{al}^{195}$ prepared folate-conjugated polymer micelles by mixing FA-PEG-DSPE and MPEG-DSPE to encapsulate the anticancer agent 9-NC. The FA-conjugated micelles have a small average size (21-24 $\mathrm{nm})$ and high encapsulation efficiency (97.6\%), which can effectively solubilize 9-NC and avoid macrophages in vitro, and has a more potent antitumor activity than those of drug-loaded MPEG-DSPE micelles and free anticancer agents. Moreover, vasoactive intestinal peptide (VIP)-grafted sterically stabilized phospholipid nanomicelles (SSMs) have been developed in order to increase the solubility of 17-allylamino-17-demethoxy geldanamycin (17-AAG) and reduce hepatotoxicity. The results demonstrated that 17-AAG could be solubilized at therapeutically relevant concentrations in actively targeted VIP surface-grafted SSM. The delivery system effectively reduced hepatotoxicity by means of dimethylsulfoxide and cremophor. However, the cytotoxicity of VIP that grafted 
nanomicelles to MCF-7 cells was significantly higher than that of 17-AAG loaded in the nontargeted SSMs.

\section{Microemulsions}

Microemulsions contain lipophilic agents without any inner water phase, which may be a more suitable carrier for the delivery of lipophilic drugs. The microemulsions prepared with PEG-DSPE have many advantages, such as enhancing the capacity of loading the hydrophobic drugs, increasing the blood-circulation time, and improving the bioavailability, in delivering drugs to tumors. ${ }^{96,97}$

Shiokawa et a ${ }^{98}$ constructed FA-linked microemulsions for delivering lipophilic antitumor antibiotics and aclacinomycin A utilizing FA-PEG-DSPE. The results showed that the association of the FA-PEG ${ }_{5000}$-linked microemulsion with the $\mathrm{KB}$ cells was 200 -fold higher, whereas their cytotoxicity was 90 -fold higher than those of non-FA microemulsion. Also, the FA-PEG-linked microemulsions showed 2.6-fold higher accumulation in solid tumors 24 hours after intravenous injection.

Junping et $\mathrm{al}^{99}$ prepared microemulsions of vincristine (M-VCR) and evaluated their pharmacokinetics, acute toxicity, and antitumor effects. The oil phase of the microemulsions was a vitamin E solution of oleic acid and VCR, and the surfactants were PEG-DSPE and cholesterol. They also exhibited small average diameter $(138.1 \pm 1.2 \mathrm{~nm})$ and high VCRloading efficiency $(94.6 \% \pm 4.7 \%)$ and stability. The plasma AUC of M-VCR was remarkably higher than that of the free VCR (F-VCR), and the tumor $\mathrm{AUC}_{0.08-12 \mathrm{~h}}$ of M-VCR was also significantly higher than that of F-VCR. Also, M-VCR was less toxic and more effective in antitumor behaviors than F-VCR in M5076 tumor-bearing C57BL/6 mice.

\section{Lipid polymer hybrid nanoparticles}

Polymer hybrid NPs consist of a hydrophobic polymeric core such as poly(D,L-lactic-co-glycolic acid) (PLGA) carrying poorly hydrophobic drugs that are released at a sustained rate,

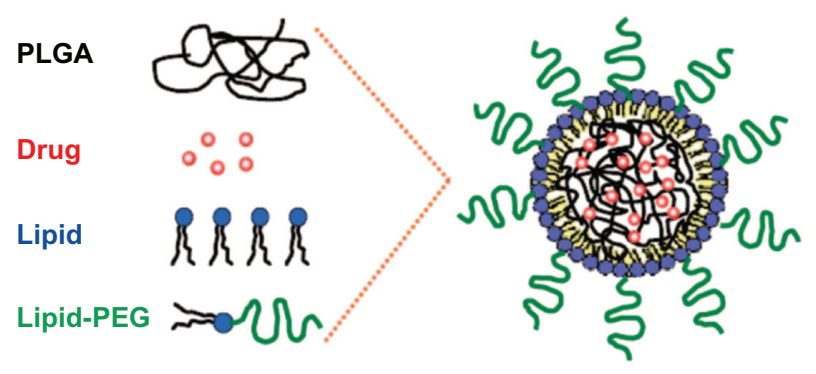

Figure 4 Schematic illustration shows the formulation of lipid polymer hybrid nanoparticles. ${ }^{100}$

Abbreviation: PLGA, poly-D,L-lactide-co-glycolide. a lipid monolayer, and an outer corona layer made of PEG, usually used lecithin and PEG-DSPE (Figure 4). ${ }^{100}$ Nanohybrid materials are subjected to chemotherapy and radiation therapy as cancer therapeutics, which is primarily attributed to the controlled production parameters by the engaged nanohybrid materials in the formation of engineered particles with specific size, shape, and other essential properties, such as the ability to be tailored to bypass the biological/physiological and immunological barriers of the body, the ability to encapsulate and deliver drugs with poor aqueous solubility profiles, and the ability to improve a drug's half-life in plasma. ${ }^{101}$

$\mathrm{Hu}$ et a ${ }^{59}$ prepared anti-carcinoembryonic antigen (antiCEA) lipid-polymer hybrid NPs loading paclitaxel for targeted drug delivery to carcinoembryonic antigen-presenting pancreatic cancer cells. Lipid polymer nanohybrids comprising PLGA as the hydrophobic polymeric core encapsulate the hydrophobic drug paclitaxel. This polymer-drug assembly was encapsulated in a lipid layer of lecithin, which was further covalently conjugated to DSPE-PEG as the hydrophilic polymer. The results showed the NPs were of small particle diameter $(95 \mathrm{~nm})$, had small negative zeta potential $(-55 \mathrm{mV})$, and fine spherical structures. They also verified the targeting specificity of the synthesized anti-CEA NPs and their enhanced cellular cytotoxicity against the target cells compared to their nontargeted counterparts.

Lipid polymer hybrid NPs have become a promising drug-delivery platform owing to their biocompatibility, biodegradability, sustained drug-release profiles, functional surface, excellent stability in blood, and most importantly, high drug-loading yield. ${ }^{100,102}$

Zhang et al ${ }^{100}$ used ester-terminated PLGA as the model hydrophobic polymer to fabricate the polymeric core of NPs encapsulating poorly water-soluble drugs, lecithin, and PEG-DSPE as the model lipid to form the PEGylated lipid monolayer. It was demonstrated that the hybrid NPs were of tunable size and surface charge, with high drug-loading yield, sustained drug-release profile, favorable stability in serum, and good cellular targeting ability.

To enhance the cellular accumulation and the retention of doxorubicin (Dox), Wong et a ${ }^{103}$ constructed a P-glycoprotein (Pgp)-modified lipid polymer hybrid NP system containing Dox using an ultrasound method. The results showed the Pgp lipid polymer hybrid NPs significantly enhanced Dox uptake and substantially increased the drug retention after treatment compared to the free Dox solutions, suggesting that phagocytosis was an essential pathway in the membrane permeability of the NPs, and lipid-based NP formulations would overcome the drug resistance in Pgp-overexpressing tumor cells. 


\section{Solid lipid nanoparticles}

In the 1990s, solid lipid nanoparticles (SLNs) including emulsions, liposomes, and polymeric ones, were developed as an alternative carrier system, which have attracted increasing attention due to improved micelle stability and industrial production adaptability. ${ }^{104,105}$ As a particulate system, SLNs refer to solid natural or synthetic lipids such as lecithin, PEG-DSPE and their derivatives, triglycerides, and other materials for carriers that are of mean particle diameters ranging from 50 to $1000 \mathrm{~nm} .{ }^{105}$ The solid core contains hydrophobic drugs dissolved or dispersed in the high melting solid lipid matrix. Stevens et al ${ }^{106}$ evaluated FA-SLN as the carrier for the lipophilic derivative of the photosensitizer hematoporphyrin (Hp). The results showed that the stability and encapsulation efficiency of the formulations did not change after being stored for 3 months at $4^{\circ} \mathrm{C}$, and FA-SLN greatly increased the cytotoxicity and cellular uptake in FR (+) KB cells compared to the nontargeted SLNs. Kuo and Liang ${ }^{107}$ prepared catanionic SLNs loading Dox-comprised DSPE-PEG $_{2000}$-carboxylic acid, DSPE-PEG ${ }_{2000}$ grafted with anti-epithelial growth factor receptor (anti-EGFR), and other components. Then the catanionic SLNs were applied to suppress the propagation of malignant U87MG cells. As a result, the optimal conditions for the preparation of antiEGFR-catanionic SLNs were 1-mM catanionic surfactants and $100 \% \mathrm{CB}$, which would inhibit the multiplication of malignant U87MG cells and substantially enhance the delivery efficiency of Dox to U87MG cells.

\section{Application of PEG-DSPE block copolymer in delivering drugs Transmission of nucleic acids}

Numerous biotech drugs have been discovered, some of which have been successfully applied in clinical use along with the development of biotechnology. Many chronic diseases such as cancer and cardiovascular dysfunction can be effectively prevented and treated utilizing biotech drugs. Nucleic acids, RNA, and DNA show huge potential in the treatment of cancer, the delivery of which would be inefficient to the target sites, though. Therefore, a delivery system is required to boost the therapeutic efficacy of labile macromolecular drugs. Currently used nanocarriers, such as liposomes, polymeric NPs, nanoemulsions, and SLNs, have proven useful to deliver nucleic acids. ${ }^{108-110}$ Also, PEG-DSPE has been widely applied in the preparation of nanocarriers for the delivery of nucleic acids as drug-carrier material.

Liposome-mediated nucleic acid delivery has been in the spotlight recently, but hurdles still exist, such as low blood stability and RES absorption, and the poor targeting of liposome seriously prevents the nucleic acid from exerting a treatment effect. ${ }^{111}$ The end group of PEG-DSPE has been modified with ligands and then inserted into the liposomes for targeted delivery, which can significantly prolong the circulation time in blood, reduce the RES absorption, increase the bioavailability of target organs, target tissues, target cells, or intracellular parts. ${ }^{110,112}$

A small, stable, long-circulating liposomal carrier for antisense oligodeoxynucleotides (asODN) was developed by Stuart et al. ${ }^{113}$ The ligand of anti-CD19 coupled with butyrate-PEG-DSPE was included in the liposomal carrier. The result showed that the majority of the asODN was cleared from blood with a half-life of more than 10 hours compared to a time of less than 1 hour for the free asODN. Anti-CD19 liposomes were also effective in delivering an MDR1 asODN to a multidrug-resistant human B-lymphoma cell line in vitro and decreasing the activity of P-glycoprotein. But the nontargeted liposomes and the free asODN did not display any inhibition.

Gene therapy has become a crucial strategy for treating a variety of human diseases including cancer, ${ }^{94}$ but its safety and effectiveness need to be improved. ${ }^{114,115}$ Thus, the development of suitable carriers for delivering therapeutic genes to target cells or tissues is meaningful and valuable.

Hayes et al ${ }^{51}$ constructed a cationic lipid-nucleic acid NP from a liquid monophase containing water and a watermiscible organic solvent where both lipid and DNA components are separately soluble prior to their combination. Then, an antibody lipopolymer (anti-HER2 scFv-PEG-DSPE) conjugate was inserted into the NPs. The result showed that PEGylation could reduce the aggregation levels of these cationic NPs in human plasma, and selectively target and transfect HER2 overexpressing cells in vitro without losing activity at higher PEG-lipid content. Also, the NPs are relatively small in size, can protect nucleic acids, and can be easily stored under a variety of conditions.

According to the poor stability of nucleic acids in the physiological fluids, selective gene inhibition by nucleic acid therapeutics realizes the treatment of diseases that cannot be cured by conventional drug carriers. Li and Huang ${ }^{41}$ developed anisamide ligand-modified sterically stabilized NPs for loading antisense oligodeoxynucleotide and siRNA into lung cancer cells. Thus, they prepared stable NPs in the presence of serum. It has been verified that anisamide ligand increased the delivery efficiency of nanoparticles by four- to sevenfold for sigma receptor overexpressing cells and provided strong antisense efficacy for downregulating surviving mRNA and 
protein, which inhibited tumor cell growth and sensitized tumor cells to anticancer drugs as a result.

\section{Transmission of nucleic acid proteins and peptides}

Recently, protein and peptide drugs in development have covered many therapeutic areas, including oncology, metabolic disorders, and cardiovascular disease. Their status primarily results from the well-known advantages of peptides as drugs, such as specificity, potency, and low toxicity. The combined sales of about 60 peptide drugs worldwide reached 13 billion in $2010 .{ }^{116}$ In addition, about 140 peptide drug candidates are in clinical development. Also, approximately 17 new peptide molecules are being clinically investigated every year now, compared to only about ten during the 1990s and about five in the 1980s ${ }^{116}$ However, the development of bioactive proteins and peptides as therapeutic agents is severely limited in most cases by their lack of oral bioavailability, poor stability, no special target, and rapid clearance from the blood. ${ }^{117,118}$ Thus PEG-DSPE was selected for the preparation of long-circulating liposomes according to previous reports to prolong the duration of proteins and peptides. ${ }^{118}$ Lim et al ${ }^{119}$ constructed sterically stabilized phospholipid nanomicelles carrying vasoactive intestinal peptide (VIP), glucagon-like peptide 1 (GLP-1), and gastric inhibitory peptide (GIP) during lyophilization. The peptide drugs were successfully lyophilized to potentially increase the shelf life of these products due to the possible decrease of drug and lipid degradation in the dried state.

Lajavardi et $\mathrm{a}^{120}$ prepared liposomes containing VIP to increase its bioavailability and efficiency. The results showed that 24 hours after intravitreal injection of VIPliposomes, VIP concentration in ocular fluids was 15 times higher than after saline/VIP injection. VIP was internalized by macrophages and polymorphonuclear leukocytes, and VIP colocalized with liposomes at least up to 14 days after injection. VIP was efficient at reducing endotoxin-induced uveitis only when formulated in liposomes.

To overcome the sequential delivery barriers, some researchers ${ }^{121,122}$ developed multifunctional modified carriers attached with multiple different ligands. Cheng and Saltzman ${ }^{122}$ used two different targeted ligands for targeting delivery: (1) folic acid as targeting ligands to elicit cell surface binding and receptor-mediated endocytosis; and (2) penetratin (ANTP) as endosomal escape ligands. The results showed folate increased the carrier avidity by binding extracellular folate receptors, which also enhanced cell uptake by triggering receptor-mediated endocytosis. Also, ANTP enhanced cell uptake by translocation across the plasma membrane, but it may also increase NP avidity through electrostatic interactions between basic peptide residues on the negatively charged cell surface.

\section{Transmission of hydrophobic drugs}

Many important active agents such as docetaxel and camptothecin are poorly soluble. In the pharmacological respect, hydrophobicity is conductive to the drug-tissue relation, and thus the formulation, solubilization, and stabilization of these agents ought to be solved. In aqueous media, amphiphilic PEG-DSPE block copolymers can self-assemble into polymeric micelles with a core-shell structure. Then the poorly soluble drugs would incorporate with the core of DSPE, which would increase the concentrations of hydrophobic drugs, improve bioavailability, and protect the drugs from inactivation in biological media. ${ }^{123,124}$

To enhance the intracellular uptake of liposomes into tumor cells, Xiong et al ${ }^{125}$ synthesized RGD mimetic (RGDm), conjugated RGDm to the end group of PEG-DSPE, and then prepared sterically stabilized targeting liposomes (SSL) modified with RGDm. DOX cellular uptake significantly increased by approximately twofold due to the intracellular uptake of RGDm ligand in vitro and the distribution of DOX by confocal microscopy analysis. DOX levels in blood, liver, spleen, kidneys, heart, and lungs after intravenous injection of SSL-DOX, RGDm-SSL-DOX, or free DOX were compared. RGDm-SSL-DOX and SSL-DOX produced increased accumulation of DOX in tumors compared to the free DOX. The AUC value of tumor for RGDm-SSL-DOX or SSL-DOX was twofold higher than that for the free DOX. RGDm-SSL-DOX did not exhibit significantly higher tumor accumulation compared to SSL-DOX.

The RGD was coupled to the distal end of the PEG-coated liposomes by Xiong et $\mathrm{al},{ }^{39}$ to increase tumor accumulation and enhance intracellular uptake. The results showed that RGD liposomes could facilitate DOX uptake into melanoma cells by integrin-mediated endocytosis. RGD-liposome-DOX displayed higher cytotoxicity on melanoma cells than liposome-DOX. RGD-liposome-DOX demonstrated prolonged circulation time and increased tumor accumulation; as SSL-DOX did, it showed remarkably higher splenic uptake than liposome-DOX. Also, RGD-liposome-DOX showed effective retardation in tumor growth compared with those receiving the same dose of SSL-DOX, free DOX solution, or saline.

\section{Summary and future perspectives}

As reviewed herein, PEG-DSPE block-copolymers with favorable biocompatibility and amphiphilic characteristics 
can be widely prepared into various carriers, such as PEGylated liposomes, polymeric NPs, microemulsions, lipid polymer hybrid NPs, and SLNs. Particularly, they are of great potential in delivering nucleic acids, proteins, and peptides as carrier materials. Also, the terminal groups of PEG-DSPE can be readily activated and modified with ligands. The recently developed PEG-DSPE derivatives not only help to overcome some practical issues such as the partial hydrolysis that the NPs might undergo during the assay but also provide highly specific quantitative analysis.

However, the development of nanocarriers is still confronting challenges. Firstly, these PEG moieties undesirably respond to prolonged circulation (eg, the long-lived antibody responses to the PEG component of these nanocarriers), ${ }^{126}$ accelerate blood clearing, and alter the biodistribution of repeated injections of PEGylated carriers. ${ }^{127,128}$ Secondly, the synthesis of PEG-DSPE block-copolymer is expensive, which requires accurate design of block copolymers to realize in vivo targeting and thus is not suitable for large-scale production. Therefore, it is necessary to develop novel approaches that can be applied to overcome the above problems. More basic research is under way to clarify the mechanisms of PEG-DSPE block copolymers and their derivatives concerning target cells in vivo.

\section{Acknowledgments}

This work was supported by grants from National Natural Science Foundation of China (81001647), China Postdoctoral Science Foundation (20100471757), and Zhejiang Provincial Innovative Incubation Projects for University Students (Emerging Artists Talents Scheme) (2011R421049).

\section{Disclosure}

The authors report no conflicts of interest in this work.

\section{References}

1. Zhang L, Chan JM, Gu FX, et al. Self-assembled lipid- polymer hybrid nanoparticles: a robust drug delivery platform. ACS Nano. 2008;2(8): 1696-1702.

2. Dos Santos N, Allen C, Doppen AM, et al. Influence of poly(ethylene glycol) grafting density and polymer length on liposomes: relating plasma circulation lifetimes to protein binding. Biochim Biophys Acta. 2007; 1768(6):1367-1377.

3. Yamada A, Taniguchi Y, Kawano K, Honda T, Hattori Y, Maitani Y. Design of folate-linked liposomal doxorubicin to its antitumor effect in mice. Clin Cancer Res. 2008;14(24):8161-8168.

4. Sriwongsitanont S, Ueno M. Effect of a PEG lipid (DSPE-PEG2000) and freeze-thawing process on phospholipid vesicle size and lamellarity. Colloid Polym Sci. 2004;282(7):753-760.

5. Brannon-Peppas L, Blanchette JO. Nanoparticle and targeted systems for cancer therapy. Adv Drug Deliv Rev. 2004;56(11):1649-1659.
6. Song S, Liu D, Peng J, et al. Peptide ligand-mediated liposome distribution and targeting to EGFR expressing tumor in vivo. Int $J$ Pharm. 2008;363(1-2):155-161.

7. Kang H, O’Donoghue MB, Liu H, Tan W. A liposome-based nanostructure for aptamer directed delivery. Chem Commun. 2010; 46(2):249-251.

8. Su JC, Tseng CL, Chang TG, Yu WJ, Wu SK. A synthetic method for peptide-PEG-lipid conjugates: application of octreotide-PEG-DSPE synthesis. Bioorg Med Chem Lett. 2008;18(16):4593-4596.

9. Karathanasis E, Geigerman CM, Parkos CA, Chan L, Bellamkonda RV, Jaye DL. Selective targeting of nanocarriers to neutrophils and monocytes. Ann Biomed Eng. 2009;37(10):1984-1992.

10. Vaidya B, Agrawal G, Vyas SP. Platelets directed liposomes for the delivery of streptokinase: development and characterization. Eur $J$ Pharm Sci. 2011;44(5):589-594.

11. Ishida O, Maruyama K, Tanahashi H, et al. Liposomes bearing polyethyleneglycol-coupled transferrin with intracellular targeting property to the solid tumors in vivo. Pharm Res. 2001;18(7): 1042-1048.

12. Lopez-Barcons LA, Polo D, Reig F, Fabra A. Pentapeptide YIGSRmediated HT-1080 fibrosarcoma cells targeting of adriamycin encapsulated in sterically stabilized liposomes. J Biomed Mater Res A. 2004; 69A(1):155-163.

13. Otsubo T, Maruyama K, Maesaki S, et al. Long-circulating immunoliposomal amphotericin B against invasive pulmonary aspergillosis in mice. Antimicrob Agents Chemother. 1998;42(1):40-44.

14. Maruyama K, Takizawa T, Yuda T, Kennel SJ, Huang L, Iwatsuru M. Targetability of novel immunoliposomes modified with amphipathic poly(ethylene glycol)s conjugated at their distal terminals to monoclonal antibodies. Biochim Biophys Acta. 1995;1234(1):74-80.

15. Zalipsky S, Brandeis E, Newman MS, Woodle MC. Long circulating, cationic liposomes containing amino-PEG-phosphatidylethanolamine. FEBS Lett. 1994;353(1):71-74.

16. Goren D, Horowitz A, Zalipsky S, Woodle M, Yarden Y, Gabizon A Targeting of stealth liposomes to erbB-2 (Her/2) receptor: in vitro and in vivo studies. Br J Cancer. 1996;74(11):1749-1756.

17. Koning GA, Morselt HWM, Gorter A, et al. Interaction of differently designed immunoliposomes with colon cancer cells and Kupffer cells. An in vitro comparison. Pharm Res. 2003;20(8):1249-1257.

18. Zalipsky S. Synthesis of an end-group functionalized polyethylene glycol-lipid conjugate for preparation of polymer-grafted liposomes. Bioconjug Chem. 1993;4(4):296-299.

19. Cuong NV, Hsieh MF. Molecular targeting of liposomal nanoparticles to lymphatic system. Curr Cancer Drug Targets. 2011;11(2): $147-155$.

20. Pan X, Wu G, Yang W, Barth RF, Tjarks W, Lee RJ. Synthesis of cetuximab-immunoliposomes via a cholesterol-based membrane anchor for targeting of EGFR. Bioconjug Chem. 2007;18(1):101-108.

21. Koning GA, Kamps JAAM, Scherphof GL. Efficient intracellular delivery of 5-fluorodeoxyuridine into colon cancer cells by targeted immunoliposomes. Cancer Detect Prev. 2002;26(4):299-307.

22. Lu RM, Chang YL, Chen MS, Wu HC. Single chain anti-c-Met antibody conjugated nanoparticles for in vivo tumor-targeted imaging and drug delivery. Biomaterials. 2011;32(12):3265-3274.

23. Kibria G, Hatakeyama H, Ohga N, Hida K, Harashima H. Dual-ligand modification of PEGylated liposomes shows better cell selectivity and efficient gene delivery. J Control Release. 2011;153(2):141-148.

24. Kirpotin D, Park JW, Hong K, et al. Sterically stabilized anti-HER2 immunoliposomes: design and targeting to human breast cancer cells in vitro. Biochemistry. 1997;36(1):66-75.

25. Gabizon A, Horowitz AT, Goren D, et al. Targeting folate receptor with folate linked to extremities of poly(ethylene glycol)-grafted liposomes: in vitro studies. Bioconjugate Chem. 1999;10(2):289-298.

26. Zhao BJ, Ke XY, Huang Y, et al. The antiangiogenic efficacy of NGR-modified PEG-DSPE micelles containing paclitaxel (NGRM-PTX) for the treatment of glioma in rats. J Drug Target. 2011;19(5): $382-390$. 
27. Yamano S, Dai J, Yuvienco C, Khapli S, Moursi AM, Montclare JK. Modified Tat peptide with cationic lipids enhances gene transfection efficiency via temperature-dependent and caveolae-mediated endocytosis. J Control Release. 2011;152(2):278-285.

28. Turk MJ, Breur GJ, Widmer WR, et al. Folate-targeted imaging of activated macrophages in rats with adjuvant-induced arthritis. Arthritis Rheum. 2002;46(7):1947-1955.

29. Gabizon A, Tzemach D, Gorin J, et al. Improved therapeutic activity of folate-targeted liposomal doxorubicin in folate receptor-expressing tumor models. Cancer Chemother Pharmacol. 2010;66(1):43-52.

30. Riviere K, Huang Z, Jerger K, Macaraeg N, Szoka FC Jr. Antitumor effect of folate-targeted liposomal doxorubicin in KB tumor-bearing mice after intravenous administration. J Drug Target. 2011;19(1): $14-24$.

31. Allen TM. Ligand-targeted therapeutics in anticancer therapy. Nat Rev Cancer. 2002;2(10):750-763.

32. Chiu SJ, Marcucci G, Lee RJ. Efficient delivery of an antisense oligodeoxyribonucleotide formulated in folate receptor-targeted liposomes. Anticancer Res. 2006;26(2A):1049-1056.

33. Doi A, Kawabata S, Iida K, et al. Tumor-specific targeting of sodium borocaptate (BSH) to malignant glioma by transferrin-PEG liposomes: a modality for boron neutron capture therapy. J Neurooncol. 2008;87(3): 287-294.

34. Yang X, Koh CG, Liu S, et al. Transferrin receptor-targeted lipid nanoparticles for delivery of an antisense oligodeoxyribonucleotide against Bcl-2. Mol Pharm. 2008;6(1):221-230.

35. Takara K, Hatakeyama H, Ohga N, Hida K, Harashima H. Design of a dual-ligand system using a specific ligand and cell penetrating peptide, resulting in a synergistic effect on selectivity and cellular uptake. Int $J$ Pharm. 2010;396(1-2):143-148.

36. Song S, Liu D, Peng J, et al. Novel peptide ligand directs liposomes toward EGF-R high-expressing cancer cells in vitro and in vivo. FASEB J. 2009;23(5):1396-1404.

37. Zhu J, Xue J, Guo Z, Zhang L, Marchant RE. Biomimetic glycoliposomes as nanocarriers for targeting P-selectin on activated platelets. Bioconjug Chem. 2007;18(5):1366-1369.

38. Morille M, Passirani C, Letrou-Bonneval E, Benoit JP, Pitard B. Galactosylated DNA lipid nanocapsules for efficient hepatocyte targeting. Int J Pharm. 2009;379(2):293-300.

39. Xiong XB, Huang Y, Lu WL, et al. Intracellular delivery of doxorubicin with RGD-modified sterically stabilized liposomes for an improved antitumor efficacy: In vitro and in vivo. J Pharm Sci. 2005;94(8): $1782-1793$

40. Jiang J, Yang S, Wang J, et al. Sequential treatment of drug-resistant tumors with RGD-modified liposomes containing siRNA or doxorubicin. Eur J Pharm Biopharm. 2010;76(2):170-178.

41. Li SD, Huang L. Targeted delivery of antisense oligodeoxynucleotide and small interference RNA into lung cancer cells. Mol Pharm. 2006; 3(5):579-588.

42. Önyüksel H, Mohanty PS, Rubinstein I. VIP-grafted sterically stabilized phospholipid nanomicellar 17-allylamino-17-demethoxy geldanamycin: a novel targeted nanomedicine for breast cancer. Int J Pharm. 2009; 365(1-2):157-161.

43. Thie H, Meyer T, Schirrmann T, Hust M, Dubel S. Phage display derived therapeutic antibodies. Curr Pharm Biotechnol. 2008;9(6): 439-446.

44. Carter P. Improving the efficacy of antibody-based cancer therapies. Nat Rev Cancer. 2001;1(2):118-129.

45. Maynard J, Georgiou G. Antibody engineering. Annu Rev Biomed Eng. 2000;2(1):339-376.

46. Sapra P, Allen TM. Improved outcome when B-cell lymphoma is treated with combinations of immunoliposomal anticancer drugs targeted to both the CD19 and CD20 epitopes. Clin Cancer Res. 2004;10(7): 2530-2537.

47. O’Donnell R, Martin S, Ma Y, Zamboni W, Tuscano J. Development and characterization of CD22-targeted pegylated-liposomal doxorubicin (IL-PLD). Invest New Drug. 2010;28(3):260-267.
48. Lopes de Menezes DE, Pilarski LM, Allen TM. In vitro and in vivo targeting of immunoliposomal doxorubicin to human B-cell lymphoma. Cancer Res. 1998;58(15):3320-3330.

49. Mamot C, Drummond DC, Greiser U, et al. Epidermal growth factor receptor (EGFR)-targeted immunoliposomes mediate specific and efficient drug delivery to EGFR-and EGFRvIII-overexpressing tumor cells. Cancer Res. 2003;63(12):3154-3161.

50. Rothdiener M, Müller D, Castro PG, et al. Targeted delivery of SiRNA to CD33-positive tumor cells with liposomal carrier systems. J Control Release. 2010;144(2):251-258.

51. Hayes M, Drummond D, Kirpotin D, et al. Genospheres: self-assembling nucleic acid-lipid nanoparticles suitable for targeted gene delivery. Gene Ther. 2005;13(7):646-651.

52. Maruyama K, Takahashi N, Tagawa T, Nagaike K, Iwatsuru M. Immunoliposomes bearing polyethyleneglycol-coupled $\mathrm{Fab}^{\prime}$ fragment show prolonged circulation time and high extravasation into targeted solid tumors in vivo. FEBS Lett. 1997;413(1):177-180.

53. Cheng WWK, Allen TM. Targeted delivery of anti-CD19 liposomal doxorubicin in B-cell lymphoma: A comparison of whole monoclonal antibody, Fab' fragments and single chain Fv. J Control Release. 2008; 126(1):50-58.

54. Allen TM, Mumbengegwi DR, Charrois GJR. Anti-CD19-targeted liposomal doxorubicin improves the therapeutic efficacy in murine B-cell lymphoma and ameliorates the toxicity of liposomes with varying drug release rates. Clin Cancer Res. 2005;11(9):3567-3573.

55. Lapalombella R, Yu B, Triantafillou G, et al. Lenalidomide downregulates the CD20 antigen and antagonizes direct and antibodydependent cellular cytotoxicity of rituximab on primary chronic lymphocytic leukemia cells. Blood. 2008;112(13):5180-5189.

56. Tuscano JM, Martin SM, Ma Y, Zamboni W, O’Donnell RT. Efficacy, biodistribution, and pharmacokinetics of $\mathrm{CD} 22$-targeted pegylated liposomal doxorubicin in a B-cell non-Hodgkin's lymphoma xenograft mouse model. Clin Cancer Res. 2010;16(10):2760-2768.

57. Drummond DC, Marx C, Guo Z, et al. Enhanced pharmacodynamic and antitumor properties of a histone deacetylase inhibitor encapsulated in liposomes or ErbB2-targeted immunoliposomes. Clin Cancer Res. 2005;11(9):3392-3401.

58. Nielsen UB, Kirpotin DB, Pickering EM, et al. Therapeutic efficacy of anti-ErbB2 immunoliposomes targeted by a phage antibody selected for cellular endocytosis. Biochim Biophys Acta. 2002;1591(1-3): $109-118$.

59. Hu CMJ, Kaushal S, Cao HST, et al. Half-antibody functionalized lipid-polymer hybrid nanoparticles for targeted drug delivery to carcinoembryonic antigen presenting pancreatic cancer cells. Mol Pharm. 2010;7(3):914-920.

60. Maruyama K, Takizawa T, Takahashi N, Tagawa T, Nagaike K, Iwatsuru M. Targeting efficiency of PEG-immunoliposome-conjugated antibodies at PEG terminals. Adv Drug Deliv Rev. 1997;24(2-3):235-242.

61. Moreira JN, Gaspar R, Allen TM. Targeting Stealth liposomes in a murine model of human small cell lung cancer. Biochim Biophys Acta. 2001;1515(2):167-176.

62. Moreira JN, Ishida T, Gaspar R, Allen TM. Use of the post-insertion technique to insert peptide ligands into pre-formed stealth liposomes with retention of binding activity and cytotoxicity. Pharm Res. 2002; 19(3):265-269.

63. Bohl Kullberg E, Bergstrand N, Carlsson J, et al. Development of EGFconjugated liposomes for targeted delivery of boronated DNA-binding agents. Bioconjug Chem. 2002;13(4):737-743.

64. Pastorino F, Brignole C, Marimpietri D, et al. Doxorubicin-loaded Fab' fragments of anti-disialoganglioside immunoliposomes selectively inhibit the growth and dissemination of human neuroblastoma in nude mice. Cancer Res. 2003;63(1):86-92.

65. Koning GA, Morselt HWM, Gorter A, et al. Pharmacokinetics of differently designed immunoliposome formulations in rats with or without hepatic colon cancer metastases. Pharm Res. 2001;18(9):1291-1298.

66. Huang L, Kennel SJ. Binding of immunoglobulin G to phospholipid vesicles by sonication. Biochemistry. 1979;18(9):1702-1707. 
67. Nobs L, Buchegger F, Gurny R, Allémann E. Current methods for attaching targeting ligands to liposomes and nanoparticles. J Pharm Sci. 2004;93(8):1980-1992.

68. Yan Z, Wang F, Wen Z, et al. LyP-1-conjugated PEGylated liposomes: a carrier system for targeted therapy of lymphatic metastatic tumor. J Control Release. 2011;157(1):118-125.

69. Gill K, Nazzal S, Kaddoumi A. Paclitaxel loaded PEG (5000)-DSPE micelles as pulmonary delivery platform: formulation characterization, tissue distribution, plasma pharmacokinetics, and toxicological evaluation. Eur J Pharm Biopharm. 2011;79(2):276-284.

70. Xu Z, Zhang Z, Chen Y, Chen L, Lin L, Li Y. The characteristics and performance of a multifunctional nanoassembly system for the co-delivery of docetaxel and iSur-pDNA in a mouse hepatocellular carcinoma model. Biomaterials. 2010;31(5):916-922.

71. Han X, Liu J, Liu M, et al. 9-NC-loaded folate-conjugated polymer micelles as tumor targeted drug delivery system: preparation and evaluation in vitro. Int J Pharm. 2009;372(1-2):125-131.

72. Shmeeda H, Amitay Y, Gorin J, et al. Delivery of zoledronic acid encapsulated in folate-targeted liposome results in potent in vitro cytotoxic activity on tumor cells. J Control Release. 2010;146(1):76-83.

73. Ishida T, Iden DL, Allen TM. A combinatorial approach to producing sterically stabilized (Stealth) immunoliposomal drugs. FEBS Lett. 1999; 460(1):129-133

74. Allen TM, Sapra P, Moase E. Use of the post-insertion method for the formation of ligand-coupled liposomes. Cell Mol Biol Lett. 2002;7(2): 217-219.

75. Iden DL, Allen TM. In vitro and in vivo comparison of immunoliposomes made by conventional coupling techniques with those made by a new post-insertion approach. Biochim Biophys. 2001;1513(2):207-216.

76. Vader P, Crielaard BJ, van Dommelen SM, van der Meel R, Storm G, Schiffelers RM. Targeted delivery of small interfering RNA to angiogenic endothelial cells with liposome-polycation-DNA particles. $J$ Control Release. 2011;160(2):211-216.

77. Woodle MC, Lasic DD. Sterically stabilized liposomes. Biochim Biophys Acta. 1992;1113(2):171-199.

78. Bakker-Woudenberg IAJM. Long-circulating sterically stabilized liposomes as carriers of agents for treatment of infection or for imaging infectious foci. Int J Antimicrob Agents. 2002;19(4):299-311.

79. Allen C, Dos Santos N, Gallagher R, et al. Controlling the physical behavior and biological performance of liposome formulations through use of surface grafted poly (ethylene glycol). Biosci Rep. 2002;22(2): 225-250.

80. Allen TM, Hansen C, Rutledge J. Liposomes with prolonged circulation times: factors affecting uptake by reticuloendothelial and other tissues. Biochim Biophys Acta. 1989;981(1):27-35.

81. Kim K, Yu M, Zong X, et al. Control of degradation rate and hydrophilicity in electrospun non-woven poly(D,L-lactide) nanofiber scaffolds for biomedical applications. Biomaterials. 2003;24(27):4977-4985.

82. Gref R, Lück M, Quellec P, et al. 'Stealth' corona-core nanoparticles surface modified by polyethylene glycol (PEG): influences of the corona (PEG chain length and surface density) and of the core composition on phagocytic uptake and plasma protein adsorption. Colloids Surf B Biointerfaces. 2000;18(3-4):301-313.

83. Bradley AJ, Murad KL, Regan KL, Scott MD. Biophysical consequences of linker chemistry and polymer size on stealth erythrocytes: size does matter. Biochim Biophys Acta. 2002;1561(2):147-158.

84. Zhu A, Lu P, Wu H. Immobilization of poly(-caprolactone)poly(ethylene oxide)-poly(-caprolactone) triblock copolymer on poly(lactide-co-glycolide) surface and dual biofunctional effects. Appl Surf Sci. 2007;253(6):3247-3253.

85. Papahadjopoulos D, Allen T, Gabizon A, et al. Sterically stabilized liposomes: improvements in pharmacokinetics and antitumor therapeutic efficacy. Proc Natl Acad Sci U S A. 1991;88(24):11460-11464.

86. Allen TM, Hansen C, Martin F, Redemann C, Yau-Young A. Liposomes containing synthetic lipid derivatives of poly(ethylene glycol) show prolonged circulation half-lives in vivo. Biochim Biophys. 1991;1066(1): 29-36.
87. Newman MS, Colbern GT, Working PK, Engbers C, Amantea MA Comparative pharmacokinetics, tissue distribution, and therapeutic effectiveness of cisplatin encapsulated in long-circulating, pegylated liposomes (SPI-077) in tumor-bearing mice. Cancer Chemother Pharm. 1999;43(1):1-7.

88. Kumari A, Yadav SK, Yadav SC. Biodegradable polymeric nanoparticles based drug delivery systems. Colloids Surf B Biointerfaces. 2010;75(1):1-18

89. Kataoka K, Harada A, Nagasaki Y. Block copolymer micelles for drug delivery: design, characterization and biological significance. Adv Drug Deliv Rev. 2001;47(1):113-131.

90. Guo J, Gao X, Su L, et al. Aptamer-functionalized PEG-PLGA nanoparticles for enhanced anti-glioma drug delivery. Biomaterials. 2011;32(31):8010-8020.

91. Yang XZ, Dou S, Sun TM, Mao CQ, Wang HX, Wang J. Systemic delivery of siRNA with cationic lipid assisted PEG-PLA nanoparticles for cancer therapy. J Control Release. 2011;156(2):203-211.

92. Diao YY, Li HY, Fu YH, et al. Doxorubicin-loaded PEG-PCL copolymer micelles enhance cytotoxicity and intracellular accumulation of doxorubicin in adriamycin-resistant tumor cells. Int J Nanomed. 2011;6:1955-1962.

93. Shi J, Xiao Z, Kamaly N, Farokhzad OC. Self-assembled targeted nanoparticles: evolution of technologies and bench to bedside translation. Acc Chem Res. 2011;44(10):1123-1134.

94. Hattori Y, Maitani Y. Enhanced in vitro DNA transfection efficiency by novel folate-linked nanoparticles in human prostate cancer and oral cancer. J Control Release. 2004;97(1):173-183.

95. Han X, Liu J, Liu M, et al. 9-nitro-camptothecin-loaded folate-conjugated polymer micelles as tumor targeted drug delivery system: preparation and evaluation in vitro. Int J Pharm. 2009;372(1-2):125-131.

96. Wang J, Maitani Y, Takayama K. Antitumor effects and pharmacokinetics of aclacinomycin A carried by injectable emulsions composed of vitamin E, cholesterol, and PEG-lipid. J Pharm Sci. 2002;91(4): 1128-1134.

97. Stevens PJ, Lee RJ. A folate receptor-targeted emulsion formulation for paclitaxel. Anticancer Res. 2003;23(6C):4927-4931.

98. Shiokawa T, Hattori Y, Kawano K, et al. Effect of polyethylene glycol linker chain length of folate-linked microemulsions loading aclacinomycin A on targeting ability and antitumor effect in vitro and in vivo. Clin Cancer Res. 2005;11(5):2018-2025.

99. Junping W, Takayama K, Nagai T, Maitani Y. Pharmacokinetics and antitumor effects of vincristine carried by microemulsions composed of PEG-lipid, oleic acid, vitamin E and cholesterol. Int J Pharm. 2003; 251(1-2):13-21.

100. Zhang L, Chan JM, Gu FX, et al. Self-assembled lipid-polymer hybrid nanoparticles: a robust drug delivery platform. ACS Nano. 2008;2(8): 1696-1702.

101. Prakash S, Malhotra M, Shao W, Tomaro-Duchesneau C, Abbasi S. Polymeric nanohybrids and functionalized carbon nanotubes as drug delivery carriers for cancer therapy. Adv Drug Deliv Rev. 2011; 63(14-15):1340-1351.

102. Chan JM, Zhang L, Yuet KP, et al. PLGA-lecithin-PEG core-shell nanoparticles for controlled drug delivery. Biomaterials. 2009;30(8): 1627-1634.

103. Wong HL, Bendayan R, Rauth AM, Xue HY, Babakhanian K, Wu XY. A mechanistic study of enhanced doxorubicin uptake and retention in multidrug resistant breast cancer cells using a polymer-lipid hybrid nanoparticle system. J Pharmacol Exp Ther. 2006;317(3):1372-1381.

104. Müller R, Radtke M, Wissing S. Solid lipid nanoparticles (SLN) and nanostructured lipid carriers (NLC) in cosmetic and dermatological preparations. Adv Drug Deliv Rev. 2002;54:S131-S155.

105. Müller RH, Mäder K, Gohla S. Solid lipid nanoparticles (SLN) for controlled drug delivery - a review of the state of the art. Eur J Pharm Biopharm. 2000;50(1):161-177.

106. Stevens PJ, Sekido M, Lee RJ. Synthesis and evaluation of a hematoporphyrin derivative in a folate receptor-targeted solid-lipid nanoparticle formulation. Anticancer Res. 2004;24(1):161-165. 
107. Kuo YC, Liang CT. Catanionic solid lipid nanoparticles carrying doxorubicin for inhibiting the growth of U87MG cells. Colloids Surf B Biointerfaces. 2011;85(2):131-137.

108. Hayes M, Drummond D, Hong K, Park J, Marks J, Kirpotin D. Assembly of nucleic acid-lipid nanoparticles from aqueous-organic monophases. Biochim Biophys Acta. 2006;1758(4):429-442.

109. Dass CR, Choong PFM. Selective gene delivery for cancer therapy using cationic liposomes: in vivo proof of applicability. J Control Release. 2006;113(2):155-163.

110. Kim JK, Choi SH, Kim CO, Park JS, Ahn WS, Kim CK. Enhancement of polyethylene glycol (PEG)-modified cationic liposome-mediated gene deliveries: effects on serum stability and transfection efficiency. J Pharm Pharmacol. 2003;55(4):453-460.

111. Owens DE III, Peppas NA. Opsonization, biodistribution, and pharmacokinetics of polymeric nanoparticles. Int J Pharm. 2006;307(1): 93-102.

112. Zuhorn IS, Engberts JBFN, Hoekstra D. Gene delivery by cationic lipid vectors: overcoming cellular barriers. Eur Biophys J. 2007;36(4): 349-362.

113. Stuart DD, Kao GY, Allen TM. A novel, long-circulating, and functional liposomal formulation of antisense oligodeoxynucleotides targeted against MDR1. Adv Exp Med Biol. 2000;7(3):466-475.

114. Gura T. After a setback, gene therapy progresses ... gingerly. Science. 2001;291(5509):1692-1697.

115. Kohn DB, Sadelain M, Glorioso JC. Occurrence of leukaemia following gene therapy of X-linked SCID. Nat Rev Cancer. 2003;3(7): 477-488.

116. Thayer AM. Improving peptides. Chem Eng News. 2011;89(22): 13-20.

117. Lu Y, Yang J, Sega E. Issues related to targeted delivery of proteins and peptides. AAPS J. 2006;8(3):466-478.

118. Woodle MC, Storm G, Newman MS, et al. Prolonged systemic delivery of peptide drugs by long-circulating liposomes: illustration with vasopressin in the Brattleboro rat. Pharm Res. 1992;9(2):260-265.
119. Lim SB, Rubinstein I, Önyüksel H. Freeze drying of peptide drugs self-associated with long-circulating, biocompatible and biodegradable sterically stabilized phospholipid nanomicelles. Int J Pharm. 2008; 356(1-2):345-350.

120. Lajavardi L, Bochot A, Camelo S, et al. Downregulation of endotoxininduced uveitis by intravitreal injection of vasoactive intestinal peptide encapsulated in liposomes. Invest Ophthalmol Vis Sci. 2007;48(7): 3230-3238.

121. Kibria G, Hatakeyama H, Harashima H. A new peptide motif present in the protective antigen of anthrax toxin exerts its efficiency on the cellular uptake of liposomes and applications for a dual-ligand system. Int J Pharm. 2011;412(1-2):106-114.

122. Cheng CJ, Saltzman WM. Enhanced siRNA delivery into cells by exploiting the synergy between targeting ligands and cell-penetrating peptides. Biomaterials. 2011;32(26):6194-6203.

123. Zhai G, Wu J, Yu B, Guo C, Yang X, Lee RJ. A transferrin receptortargeted liposomal formulation for docetaxel. J Nanosci Nanotechnol. 2010;10(8):5129-5136.

124. Vladimir PT. Structure and design of polymeric surfactant-based drug delivery systems. J Control Release. 2001;73(2-3):137-172.

125. Xiong XB, Huang Y, Lu WI, et al. Enhanced intracellular delivery and improved antitumor efficacy of doxorubicin by sterically stabilized liposomes modified with a synthetic RGD mimetic. J Control Release. 2005;107(2):262-275

126. Judge A, McClintock K, Phelps JR, MacLachlan I. Hypersensitivity and loss of disease site targeting caused by antibody responses to PEGylated liposomes. Mol Ther. 2006;13(2):328-337.

127. Ishida T, Maeda R, Ichihara M, Irimura K, Kiwada H. Accelerated clearance of PEGylated liposomes in rats after repeated injections. $J$ Control Release. 2003;88(1):35-42.

128. Dams E, Laverman P, Oyen WJG, et al. Accelerated blood clearance and altered biodistribution of repeated injections of sterically stabilized liposomes. J Pharmacol Exp Ther. 2000;292(3):1071-1079.
International Journal of Nanomedicine

\section{Publish your work in this journal}

The International Journal of Nanomedicine is an international, peerreviewed journal focusing on the application of nanotechnology in diagnostics, therapeutics, and drug delivery systems throughout the biomedical field. This journal is indexed on PubMed Central, MedLine, CAS, SciSearch $\AA$, Current Contents ${ }^{\circledR} /$ Clinical Medicine,

\section{Dovepress}

Journal Citation Reports/Science Edition, EMBase, Scopus and the Elsevier Bibliographic databases. The manuscript management system is completely online and includes a very quick and fair peer-review system, which is all easy to use. Visit http://www.dovepress.com/ testimonials.php to read real quotes from published authors. 